\title{
The relationship between gastroesophageal reflux and cough in children with chronic unexplained cough using combined impedance-pH-manometry recordings
}

\begin{tabular}{|r|l|}
\hline Journal: & Pediatric Pulmonology \\
\hline Manuscript ID: & PPUL-09-0319.R2 \\
\hline Wiley - Manuscript type: & Original Article \\
\hline Date Submitted by the & 04-Jun-2010 \\
\hline Complete List of Authors: & $\begin{array}{l}\text { Blondeau, Kathleen; KULeuven, Center for Gastroenterological } \\
\text { Research } \\
\text { Mertens, Veerle; KULeuven, Center for Gastroenterological } \\
\text { Research } \\
\text { Dupont, Lieven; UZLeuven, Division of Respiratory Medicine } \\
\text { Pauwels, Ans; KULeuven, Center for Gastroenterological Research } \\
\text { Farre, Ricard; KULeuven, Center for Gastroenterological Research } \\
\text { Malfroot, Anne; Universitair Ziekenhuis Brussel, Units of Pediatric } \\
\text { Pulmonology } \\
\text { De Wachter, Elke; Universitair Ziekenhuis Brussel, Units of Pediatric } \\
\text { Pulmonology } \\
\text { De Schutter, Iris; Universitair Ziekenhuis Brussel, Units of Pediatric } \\
\text { Pulmonology } \\
\text { Hauser, Bruno; Universitair Ziekenhuis Brussel, Units of Pediatric } \\
\text { Gastroenterology } \\
\text { Vandenplas, Yvan; Universitair Ziekenhuis Brussel, Units of } \\
\text { Pediatric Gastroenterology } \\
\text { Sifrim, Daniel; KULeuven, Center for Gastroenterological Research }\end{array}$ \\
\hline Keywords: & $\begin{array}{l}\text { Non-acid gastroesophageal reflux, chronic cough, impedance-pH, } \\
\text { manometry }\end{array}$ \\
\hline & \\
\hline
\end{tabular}

\section{(5)holaroNE" \\ Manuscript Central}




\title{
The relationship between gastroesophageal reflux and cough in children with chronic unexplained cough using combined impedance-pH-manometry recordings.
}

\author{
Blondeau $K^{1}$, Mertens $V^{1}$, Dupont $L^{2}$, Pauwels $A^{1}$, Farré $R^{1}$, Malfroot $A^{3}$, De \\ Wachter $E^{3}$, De Schutter $I^{3}$, Hauser $B^{3}$, Vandenplas $Y^{3}$ and Sifrim $D^{1}$ \\ ${ }^{1}$ Center for Gastroenterological Research, K.U.Leuven, Belgium \\ ${ }^{2}$ Division of Respiratory Medicine, University Hospital Gasthuisberg, K.U.Leuven, \\ Belgium \\ ${ }^{3}$ Units of Pediatric Pulmonology and Gastroenterology, Universitair Ziekenhuis Brussel, \\ Brussels, Belgium \\ Corresponding author:

Daniel Sifrim
Faculty of Medicine K.U.Leuven
Lab G-I Physiopathology
O\&N 1 Gasthuisberg, 7th floor
Herestraat 49, 3000, Leuven, Belgium.
Tel: +32.16.345752
Fax: +32.16.345939
e-mail:Daniel.Sifrim@med.kuleuven.be

Short title: Reflux (acid and non-acid) and chronic cough in children with chronic cough. Keywords: Children, gastroesophageal reflux, impedance-pH-manometry, cough 


\begin{abstract}
Introduction Assessment of the reflux-cough association in children is challenging. Esophageal (impedance-)pH recording is sensitive to recognize reflux. However, cough recorded by an event marker, possibly lacks accuracy. We aimed to study the exact time relationship between reflux and cough in children with chronic cough. Methods 26 children (12 boys;1-10.5 years) with chronic unexplained cough underwent ambulatory impedance-pH-manomety recordings. Manometry was used for precise cough recognition. Reflux was assessed with impedance-pH monitoring and defined as acid $(\mathrm{pH}<4)$, weakly acidic (WA) $(\mathrm{pH} 4-7)$, weakly alkaline (WALK) $(\mathrm{pH} \geq 7)$ or acid only $(\mathrm{pH}<4$ for $\geq 4 \mathrm{sec}$ without impedance pattern). Cough was considered "induced by" reflux, if it started $\leq 2 \mathrm{~min}$ after reflux. The Symptom Association Probability (SAP) was calculated and considered positive if $>95 \%$. Cough induced reflux if it occurred $30 \mathrm{sec}$ before the reflux event. Results Impedance-pH detected 30(21-52) reflux episodes/patient (55.2\% acid, $41.5 \%$ WA and 3.3\% WALK). Additionally 59 acid only events were identified [1(021)/patient]. Manometry detected 47(5-203) cough bursts/patient. Reflux-cough was found in 22/26 patients. Ten patients had a +SAP for reflux-cough ( 1 acid, 6 WA and 3 acid+WA GER), of which 9 had a normal acid exposure. 6/10 patients with +SAP using manometry had a +SAP using the event marker. Cough-reflux was detected in 19 patients [3(0-7)/patient]. Only a small fraction of the esophageal acid exposure [9.6 (0.4$31.8 \%)$ ] was secondary to cough. Conclusion Both acid and WA GER may precede cough in children with unexplained cough, but cough does not induce GER. Objective cough recording improves symptom association analysis.
\end{abstract}




\section{INTRODUCTION}

Both cough and gastroesophageal reflux (GER) in infants and children are common reasons for parents to seek medical attention. ${ }^{1}$ Although GER has been recognized as a cause for unexplained cough, diagnosing GER related cough in children is still challenging. The presence of symptoms suggestive for GER disease, e.g. regurgitation, vomiting, failure to thrive, is often a first indication ${ }^{2}$, but the absence of these symptoms cannot exclude GER as an underlying cause of the chronic cough.

Several diagnostic techniques, including proximal $\mathrm{pH}$ recording and detection of lipid laden macrophages in the Broncho-Alveolar Lavage Fluid (BALF) have been used for the diagnosis of proximal reflux and aspiration of gastric contents into the lungs. ${ }^{3-5}$ However, proximal reflux is not required as the presence of gastric contents in the distal esophagus might induce a vagal reflex leading to cough. ${ }^{6 ; 7}$

Ambulatory esophageal $\mathrm{pH}$-metry has long been considered an important tool for the detection of acid reflux. More recently, combined esophageal impedance-pH recordings have shown that not only acid but also non-acid reflux might be associated with respiratory symptoms such as cough..$^{8-12}$

Symptom association analysis requires an accurate registration of symptoms, which previously has been performed using an event marker. ${ }^{10 ; 13}$. Since in children symptom recording is mostly controlled by the parents, the use of an event marker may imply that the timing of registration might be delayed compared to the actual occurrence of the symptom and that symptoms might be missed. Moreover, especially in patients with cough, an accurate timing of symptom recording is important since reflux may not only induce cough, but cough might also induce reflux. ${ }^{6 ; 14}$ To which extent the latter is important in children with chronic cough remains unknown.

Ambulatory 24 hours esophageal manometry has been proven a useful tool for objective recognition of cough in patients undergoing 24 hours reflux testing and for establishing the exact time relationship between reflux and cough events. ${ }^{8 ; 15 ; 16}$.

The aim of the current study was therefore to use combined ambulatory 24 hours impedance-pH-manometry recordings to study acid and non-acid GER and its relationship to cough in children with chronic unexplained cough. 


\section{METHODS}

\section{Subjects}

Simultaneous 24 hours ambulatory esophageal manometric-impedance-pH monitoring was performed in 26 children with chronic unexplained cough (12 boys; median age 4 years, range 1-10.5 years). The patients were recruited at the outpatient clinic of the Universitair Ziekenhuis Brussel, and presented daily cough of unclear etiology for at least 8 weeks. Those with an alternative diagnosis, such as clinical suspected asthma responding to a treatment trial during at least 4 weeks, underlying ENT problems or upper airway cough syndrome, pertussis, cystic fibrosis, tuberculosis, cardiac disease, chromosomal or humoral immunological deficiency were excluded from the study after workup as listed in Table1. ${ }^{17}$

None of the children received acid suppressing therapy. The study was approved by the local ethical committee. Informed consent was given prior to inclusion.

\section{Recording equipment and technique}

Cough and GER were monitored simultaneously using an ambulatory manometricimpedance-pH system. Manometry was used for accurate cough recognition whereas impedance-pH monitoring allowed detection of acid, weakly acidic and weakly alkaline reflux.

A manometric catheter with 2 solid-state pressure sensors (15 cm apart) (Sandhill Scientific, Inc; Highlands Ranch, CO, USA) (1.3 mm external diameter) was passed transnasally. The catheter was positioned so that one pressure channel was located in the esophageal body and the other in the stomach. Esophageal impedance-pH was recorded with a $2.1 \mathrm{~mm}$ diameter catheter that comprised six electrode pairs to measure intraluminal impedance and 2 antimony $\mathrm{pH}$ sensors (Sandhill Scientific, Inc; Highlands Ranch, CO, USA). Two different types of age appropriate catheters were used: infant (< $75 \mathrm{~cm}$ of height) and pediatric (> $75 \mathrm{~cm}$ of height).The impedance-pH and manometric 
catheters were connected to a single ambulatory device containing their respective amplifiers (Sleuth, Sandhill Scientific, Inc; Highlands Ranch, CO, USA). The impedance amplifier delivered ultra-low current in a range of $1-2 \mathrm{KHz}$ with resulting current flow variations in response to intraluminal impedance changes. The impedance, $\mathrm{pH}$ and manometric signals were digitized at $50 \mathrm{~Hz}$ and stored in the data logger. Before the start of the recording, the $\mathrm{pH}$ electrodes were calibrated using $\mathrm{pH} 4.0$ and $\mathrm{pH} 7.0$ buffer solutions.

\section{Study protocol}

The study was performed after an overnight fast. The catheters were passed transnasally and positioned to record pressures and $\mathrm{pH}$ in the stomach and pressure $\mathrm{pH}$ and impedance in the esophageal body. Impedance-pH catheter was positioned so that the esophageal $\mathrm{pH}$ sensor was at the third vertebral body above the diaphragmatic angle. The patients were encouraged to maintain normal activities, sleep schedule, and eat their usual meals at their normal times. Event markers on the data logger recorded meal times and posture changes. Between meals, patients abstained from snacks and beverages with $\mathrm{a} \mathrm{pH}<5$. Before the study, parents were instructed to keep a careful diary and trained to use a dedicated event marker in the data logger, to record cough episodes and other events.

\section{Data analysis}

The manometric-impedance-pH recordings were uploaded into a personal computer and were manually analysed using dedicated software (Bioview, Sandhill Scientific, USA ).

\section{$\underline{\text { Cough detection }}$}

The manometric tracing was independently analysed for cough episodes. Cough was defined according to Paterson et al. as phasic, short duration, rapid pressure rises (time to peak $<1 \mathrm{sec}$ ) occurring simultaneously and with the same pressure configuration at both manometric recording sites. ${ }^{15}$ A "cough burst" was defined as two or more rapid simultaneous pressure peaks within 3 seconds. Only "cough bursts" were considered in the further analysis. The cough events marked in the data logger and diary information were used for comparison with objective detection of cough bursts by manometry. 


\section{$\underline{\text { Reflux detection }}$}

The impedance-pH recording was analysed for GER, independently of the pressure recordings. The impedance recording was analysed using criteria described in a recent consensus report on detection and definitions of acid, non-acid, and gas reflux. ${ }^{18}$ GER was defined as a sequential orally progressing drop in impedance to less than $50 \%$ of the baseline values starting at the most distal channel and propagating retrograde to at least the next more proximal measuring segment. According to the corresponding $\mathrm{pH}$ change, impedance-detected reflux was classified as acid if $\mathrm{pH}$ fell below 4 for at least 4 seconds, if $\mathrm{pH}$ was already below 4 , as a decrease of at least $1 \mathrm{pH}$ unit sustained for more than 4 seconds. Weakly acidic reflux was defined as a pH drop of at least $1 \mathrm{pH}$ unit sustained for more than 4 seconds with the basal $\mathrm{pH}$ remaining between 7 and 4 . Reflux was judged to be weakly alkaline when there was impedance evidence of reflux but the pH did not drop below 7.

Acid only events were defined as a drop in the esophageal $\mathrm{pH}$ below 4 for at least $4 \mathrm{sec}$ without a characteristic reflux pattern in the impedance tracing.

For each reflux episode determined by $\mathrm{pH}$-impedance, the associated gas-liquid pattern was classified as: (i) mixed reflux of liquid and gas or (ii) liquid reflux. Only gas reflux episodes (belches) were not included in the analysis. The proximal extent of each reflux event was evaluated from the impedance tracings. For each patient, the total number of reflux events (acid, weakly acidic and weakly alkaline), the number of episodes reaching the proximal esophagus ( $\mathrm{nr}$ of episodes reaching impedance channel 1 ) and the exposure of the esophageal body to acid and volume were calculated.

Total 24 hours acid exposure was calculated as the percentage of time that the esophageal $\mathrm{pH}$ was below 4 and was considered increased if $>6 \%$ of the total recording time. ${ }^{19}$ This parameter included all $\mathrm{pH}$ drops either related or not related to bolus reflux. For each reflux episode detected by impedance, volume exposure in impedance channel 5, was calculated as the time ( $\mathrm{sec}$ ) between the 50\% drop in impedance until the 50\% recovery of the impedance baseline. Total volume exposure/24 hours was obtained by addition of the volume exposures of all individual reflux events.

\section{Association reflux-cough}

A 2 minute time interval following the start of a reflux episode was used to delimitate the time window for reflux-cough association. A 2 minute period was chosen based on 
previous analysis of acid reflux-chest pain association. ${ }^{20}$ Thus, if a cough episode occurred in the 2 minute time period after the start of a reflux event, cough was considered "associated to reflux". (Figure 1) If cough fell outside the 2 minutes time window after reflux, it was considered to have occurred "independent" of reflux. We calculated for each patient the symptom association probability (SAP) between cough and different types of reflux (acid and weakly acidic). (software Dr Tutuian) The entire recording was subdivided into consecutive 2 minute time intervals. Each time interval was evaluated for the presence of reflux. When reflux was detected at any point during the 2 minute period, the period was considered positive for reflux $(R+)$. In a second step, the 2 minute periods containing a reflux episode followed by cough $\left(R_{+} S_{+}\right)$, those with only cough but no reflux (R-S+) and those with neither cough nor reflux (R-S-) were counted. A contingency table was constructed containing the number of the four different types of 2 minute periods. Fisher's exact test was used to calculate the probability ( $P$ value) that the observed association between reflux and cough occurred by chance. The SAP was calculated as $(1.0-p)^{*} 100 \%$. SAP values greater than $95 \%$ were considered statistically significant. ${ }^{21 ; 22}$

\section{Association cough-reflux}

Cough episodes preceding a reflux event were evaluated separately.

A reflux event was considered "induced by" cough if cough occurred in the 30 seconds preceding reflux. ${ }^{15}$ (Figure 2) The total esophageal acid and volume exposures due to cough were calculated by adding the acid and volume exposures (sec) at $5 \mathrm{~cm}$ above the LES from the individual reflux events "induced by" cough, divided by the total recording time.

\section{Statistical analysis}

Data are presented as median (range) unless otherwise stated. If data were normally distributed the paired Student's $t$ test was used for comparison. If data were not normally distributed a non-parametric Mann-Whitney test was applied. Fisher's exact test was used to calculate SAP. Statistical significance was accepted when $p<0.05$. 


\section{RESULTS}

\section{Gastroesophageal reflux}

4 patients had symptoms suggesting GER. Two children had heartburn and/or regurgitation, 1 had abdominal pain and 1 child had frequent vomiting.

Impedance recordings detected 967 reflux events. From the total amount of reflux detected, $55.2 \%$ was acid, $41.5 \%$ was weakly acidic and $3.3 \%$ was weakly alkaline. Overall, $32 \%$ of the reflux episodes were mixed (liquid+gas) and $68 \%$ were liquid. Of all reflux events detected by impedance, $26 \%$ reached the proximal esophagus. Reflux characteristics are displayed in table 2.

In addition to the reflux events detected by impedance, 59 acid only events were identified [1(0-21)/patient]. From the total esophageal acid exposure 6.0(2.4-62.3)\% was due to acid only events. Overall, 3/26 children had an increased esophageal acid exposure. None of these children had symptoms suggesting GER. There was a significant correlation between age and the nocturnal esophageal acid exposure $(r=0.77$, $p<0.0001)$, total number of reflux events $(r=0.77, p<0.0001)$, number of acid reflux events $(r=0.74, p<0.0001)$ and the esophageal volume exposure $(r=0.79, p<0.0001)$.

\section{Cough}

Gastroesophageal manometry detected 47(5-203) cough bursts/patient, of which 4(0-65) occurred during the night.

Overall 464 cough markers were recorded in 17/26 children [8(0-75) markers/child]. There was a significant correlation between the number of coughs recorded by manometry and the number of event markers ( $r=0.73, p=0.001)$. In 9 children no cough markers were recorded. (Table 3) 
From the 464 cough markers recorded, 388 (84\%) corresponded to a cough burst identified by manometry. The event marker was pressed, 19(5-92) seconds after the start of the actual cough burst.

From the 78 event markers that did not correspond to a cough burst identified by manometry, 65 occurred in the same child. These 65 cough markers corresponded to single pressure spikes, probably representing single cough episodes.

There was no correlation between age and the number of coughs detected either by manometry or indicated by the event marker.

\section{Gastroesophageal reflux and cough}

There was no correlation between any of the reflux parameters (acid exposure, volume exposure, number of reflux events and number of proximal reflux events) and the number of coughs.

\section{$\underline{\text { Reflux-cough }}$}

From the 1404 cough bursts detected by manometry, 140 were preceded by impedance reflux (58 acid, 77 weakly acidic and 5 weakly alkaline reflux). Only 5 cough bursts were preceded by an "acid only" event.

Ten patients had a positive SAP for reflux-cough, of which 1 exclusively for acid reflux, 6 exclusively for weakly acidic and 3 patients for both acid and weakly acidic reflux.

One of the 10 patients with a +SAP had an increased esophageal acid exposure. (Figure 3) One of the patients with a +SAP (acid reflux) had symptoms suggesting reflux (abdominal pain).

Patients with a +SAP were significantly older than patients with a -SAP [Mean 5.9 \pm SD 3.3 vs. Mean $3.6 \pm$ SD 1.7 years, $p=0.03$ ]. All reflux parameters (acid exposure, volume 
exposure, number of reflux events and proximal extent of reflux) and the number of cough bursts were similar in patients with and without a +SAP.

Six out of the 10 patients with a +SAP using objective cough detection had a +SAP using the event marker for cough recognition operated by the parents. In contrast to the SAP based on the manometric recordings, 4 of these patients had a +SAP for acid reflux and only 2 patients for weakly acidic reflux. One patient had a +SAP using the cough event marker but a -SAP using manometry. (table 3)

\section{$\underline{\text { Cough-reflux }}$}

Cough-reflux sequences were found in 18/26 patients [3(0-7)/patient]. From the reflux events "induced by" cough, 43\% were acid, 41\% weakly acidic, 4.5\% weakly alkaline and $11.5 \%$ were acid only events. From the total esophageal acid $9.6 \%(0.4-31.8 \%)$ and bolus exposure $2.1 \%(0.0-28.0 \%)$ was secondary to cough.

The majority of cough-reflux events occurred during the upright period, whereas $24 \%$ occurred during a recumbent period. Thirty six percent of the cough-reflux events occurred in the first hour after the meal. 


\section{DISCUSSION}

GER is recognized as an important cause of respiratory symptoms in children, including chronic cough. ${ }^{23}$ Reflux-symptom association during 24 hours reflux recording is an important tool for the diagnosis of GER related cough. However, in children when symptom registration is performed by the parents, the use of an event marker for cough registration might lack accuracy and the reflux-cough relationship might be misinterpreted.

The aim of the current study was to study reflux and its relationship to cough using objective techniques for both reflux (impedance-pH recording) and cough (gastroesophageal manometry) detection.

Our main findings were the following: 1) Independent of an increased esophageal acid exposure, a group of children had a statistical and clinical significant association between reflux and cough. 2) Acid reflux may precede cough. However, more frequently cough was preceded by weakly acidic reflux. Weakly alkaline reflux is rare and is unlikely to precede cough. 3) Acid only events are present in children with chronic unexplained cough and contribute to the total esophageal acid exposure. However, they were not associated with cough 4) An objective technique for cough recording is important to identify the correct time relationship between reflux and cough events. 5) Cough does not provoke reflux in children with chronic unexplained cough.

Both in adults and in children, GER has been implicated in the pathophysiology of a wide variety of respiratory symptoms and diseases including chronic unexplained cough. ${ }^{1 ; 8 ; 10-}$ 12;23-25 Ambulatory 24 hours esophageal $\mathrm{pH}$ recording has demonstrated an increased acid exposure in a subgroup of children with respiratory symptoms such as cough ${ }^{10 ; 11 ; 23}$. However, 24 hours $\mathrm{pH}$-metry is limited to the detection of acid reflux. In conditions during which the gastric contents is neutralized, e.g. in the postprandial period, reflux events of non-acid $\mathrm{pH}$ may be missed. Esophageal impedance recording allows detection all types of reflux, independent of the $\mathrm{pH}$. Combining impedance with $\mathrm{pH}$ recording allows to classify reflux events based on their $\mathrm{pH}^{18 ; 26}$

The role of non-acid reflux in children with respiratory complications remains unclear. ${ }^{23}$ Rosen et al. previously studied acid and non-acid reflux using combined impedance pH 
recording in a group of children with persistent respiratory symptoms "on" PPI therapy. In patients studied during PPI treatment, $50 \%$ of the reflux events detected by $\mathrm{pH}$ impedance recordings were non-acidic ${ }^{10}$. Thilmany et al. performed a similar study in children "off" PPI therapy. They found that from the total amount of reflux detected, only $5.1 \%$ was non-acidic. ${ }^{11}$ In contrast to these findings we found that $44.8 \%$ of all reflux episodes was non-acidic. The reason for this large difference in prevalence of non-acid reflux remains uncertain. However, whereas our study included only children with chronic cough of unknown origin, the study of Thilmany et al included patients with different respiratory diseases including patients with cystic fibrosis. ${ }^{11}$ The high prevalence of especially acid reflux in this population together with inclusion of other respiratory pathologies might be related to the higher proportion of acid reflux.

In the current study non-acidic reflux was sub classified into weakly acidic ( $\mathrm{pH} \mathrm{4-7)} \mathrm{and}$ weakly alkaline $(\mathrm{pH} \geq 7)$. Our results showed that as in adults with chronic cough, weakly alkaline is rare and the majority of non-acidic events has a weakly acidic $\mathrm{pH}^{8 ; 16}$.

An absence of increased reflux does not exclude an association between reflux and symptoms. Moreover, since in children normal values for impedance-pH recording are lacking, it is impossible to judge whether non-acid reflux is increased. Simultaneous symptom and reflux recording allows to determine the time association between individual reflux and cough events and to identify whether a cough is preceded, followed by or not-associated with reflux.

Thilmany et al. previously studied the time association, using a 2 min time interval, between reflux events and episodes of oxygen desaturation. They found that overall $37.7 \%$ of all desaturation episodes were preceded by a reflux event of which the majority $(92 \%)$ were acid. ${ }^{11}$

Rosen et al. also studied the time association between reflux and a variety of respiratory symptoms including a subgroup of children with chronic cough. They used combined impedance-pH recording, a patient diary for cough registration and a 2 minute time window for reflux-cough association. They found that overall, $37.6 \%$ of the cough events recorded were associated with reflux. Per patient analysis showed a significant association between reflux and cough in $33.3 \%$ of patients using combined impedance$\mathrm{pH}$ analysis and in $5.6 \%$ of patients using only $\mathrm{pH}$ probe analysis. ${ }^{10}$

The use of an event marker for cough registration has a major limitation since the accuracy of this method depends largely on the patient's cooperation. This may even be 
more the case in children where symptom registration is performed by the parents. Symptoms episodes may be missed (e.g. during sleep) or may be recorded later than they actually occurred. The use of an objective technique for cough recording may overcome this limitation. Gastroesophageal pressure recording has been demonstrated as a useful tool for objective cough registration and has been previously used by our group and others to study the time relationship between reflux and cough events in adult patients with chronic cough. 8;15;16

In the current study we demonstrated in children with chronic cough that, as in adult patients, the use an objective technique for cough detection significantly increased the number of coughs recorded compared to the use of an event marker. The mean delay between the cough bursts and the event marker was approximately 20 seconds.

Overall $84 \%$ of the event markers corresponded to a manometric cough bursts. Although $78 / 464$ event markers did not correspond to a typical cough bursts, 65 of these were recorded in a single patient. All of the 65 markers corresponded to a single pressure spike in manometry. Since single spikes in manometry cannot be distinguished from phenomena such as sneezing, they were included in the analysis. Nevertheless, these single coughs were associated with event markers in only one child, suggesting that their clinical importance might be limited.

The most important aim of the current study was to evaluate the exact time relationship between reflux and cough events using objective techniques for both reflux and cough recordings. First of all we confirmed that not only acid but also weakly acidic reflux may precede cough. We remind that Rosen et al previously reported similar findings, but their study was performed in patients "on" PPI treatment and without the use of objective cough detection. ${ }^{10}$ Our study showed for the first time, using an objective technique for cough recording that weakly acidic reflux may "induce" cough in children "off" PPI. A significant association between reflux and cough (+SAP) was found in 10/26 (38\%) of the children, which is comparable what has been previously reported for other respiratory symptoms. Remarkable is that only 1 child had a +SAP for acid reflux, whereas all other patients had a +SAP for weakly acidic reflux either alone or in combination with acid. This finding is in line with previous observations describing that the presence of non-acid reflux was associated with an increase in reflux-symptom association. ${ }^{10}$ Weakly alkaline reflux was rare and hardly ever preceded a cough event. The reason why weakly acidic reflux is more likely to be associated with cough might be 
related to a different composition of the weakly acidic refluxate. The presence of specific chemical components (e.g. unconjugated bile acids) or an increased volume of the refluxate might promote stimulation of the vagal reflex associated with the reflux-cough pathway or might be more harmful when aspirated into the lungs.

Six out of the ten patients with a positive SAP for reflux-cough using manometry were also identified as SAP+ using the event marker. Interestingly, using the event marker most of these patients had an association between acid reflux and cough whereas with the manometry, cough was associated with weakly acidic reflux. The reason for this difference is unclear. Possibly acid reflux is more clearly perceived by the child and may lead to a change in behaviour (e.g. crying). This in term might make the parents more aware of the symptom and may stimulate them of pressing the event marker.

One child had a +SAP using the event marker but a -SAP using manometry, this was the child with the multiple single coughs.

Although impedance recording provides a high sensitivity of reflux detection, $\mathrm{pH}$ drops may occur without the typical reflux impedance pattern. These "acid only" events are found to be common, particularly in young children. In contrast to previous studies which reported a very high prevalence of acid only events, their prevalence in the current study was much lower. ${ }^{10-12}$ Moreover, although acid only events may contribute to the total esophageal acid exposure, our study showed that only 4/59 acid only events preceded cough, suggesting that they do not contribute to the reflux-cough relationship.

The relationship between reflux and cough is complex, since reflux may not only induce cough but it has been suggested that cough, by increasing the abdomino-thoracic pressure gradient, can also provoke reflux. Whether and to what extent, cough provokes reflux in children is unknown. Our study is the first to report that cough is not an important cause of reflux in children with chronic unexplained cough, since only a very small proportion of the total esophageal acid and volume exposure were secondary to cough, confirming our findings in adult patients. ${ }^{8}$ 
The current study has some limitations, including the small number of children studied. Our study focussed primarily on children with unexplained chronic cough without clear signs of excessive reflux. In children with severe reflux, the objective relationship between reflux and cough will need to be investigated.

In order to have an optimal detection of cough, a thin catheter crossing the LES was used to record both abdominal and thoracic pressures. Although the overall prevalence of reflux in the current study was low, previous studies have reported that a catheter crossing the LES might slightly enhance reflux in children and this effect cannot be excluded from our study. ${ }^{27}$

Previous studies have shown a suboptimal reproducibility of reflux measurements using $24 \mathrm{hrs} \mathrm{pH}$-recordings. Hence, it is likely that the reflux-cough association as assessed in the current study is subject to a day-to-day variability. ${ }^{28}$

Although we could establish the objective relationship between reflux and cough in this group of children with chronic unexplained cough, intervention studies will need to confirm the clinical relevance of this reflux-cough association in these patients.

In summary we can conclude that using objective techniques for reflux and cough detection, results in the observation that reflux may precede cough in a subgroup of children with chronic unexplained cough. Although acid reflux may precede cough, in most children cough was preceded by weakly acidic reflux. Weakly alkaline and acid only events are not important for the reflux-cough relationship. The use of an objective technique for cough detection increases the prevalence and accuracy of cough registration and may improve symptom association analysis. In contrast to what is often suggested, cough does not provoke a significant amount of reflux in children with chronic cough.

These findings may have important diagnostic and therapeutic implications for patients with reflux related respiratory problems. First of all our results suggested that combined impedance-pH testing is superior to $\mathrm{pH}$ testing alone. Secondly, other treatment strategies might need to be considered to treat patients with reflux related cough. In most of these patients reflux is treated with anti-acid medications, which insufficiently reduce weakly acidic reflux. ${ }^{29}$ Anti-reflux treatments affecting all types of reflux may need to be considered. However, so far pharmacological options are limited to baclofen, 


\begin{abstract}
a $\mathrm{GABA}_{b}$ agonist reducing the number of transient relaxations of the lower esophageal sphincter (LES). ${ }^{30-32}$ In some patients anti-reflux surgery may be considered.

Intervention studies will need to confirm the clinical relevance of weakly acidic reflux in children with unexplained chronic cough.
\end{abstract}

John Wiley \& Sons, Inc. 


\section{Reference List}

1. Bailey EJ, Morris PS, Kruske SG, Chang AB. Clinical pathways for chronic cough in children. Cochrane Database Syst Rev 2008;(2):CD006595.

2. Hassall E. Decisions in diagnosing and managing chronic gastroesophageal reflux disease in children. J Pediatr 2005 Mar;146(3 Suppl):S3-12.

3. Conley SF, Werlin SL, Beste DJ. Proximal pH-metry for diagnosis of upper airway complications of gastroesophageal reflux. J Otolaryngol 1995 Oct;24(5):295-8.

4. Koksal D, Ozkan B, Simsek C, Koksal AS, Agackyran Y, Sasmaz N. Lipid-laden alveolar macrophage index in sputum is not useful in the differential diagnosis of pulmonary symptoms secondary to gastroesophageal reflux. Arch Med Res 2005 Sep;36(5):485-9.

5. Krishnan U, Mitchell JD, Tobias V, Day AS, Bohane TD. Fat laden macrophages in tracheal aspirates as a marker of reflux aspiration: a negative report. J Pediatr Gastroenterol Nutr 2002 Sep;35(3):309-13.

6. Galmiche JP, Zerbib F, Bruley d, V. Review article: respiratory manifestations of gastro-oesophageal reflux disease. Aliment Pharmacol Ther 2008 Mar $15 ; 27(6): 449-64$.

7. Kollarik M, Brozmanova M. Cough and gastroesophageal reflux: insights from animal models. Pulm Pharmacol Ther 2009 Apr;22(2):130-4.

8. Blondeau K, Dupont LJ, Mertens V, Tack J, Sifrim D. Improved diagnosis of gastrooesophageal reflux in patients with unexplained chronic cough. Aliment Pharmacol Ther 2007 Mar 15;25(6):723-32. 
9. Blondeau K, Dupont L, Mertens V, Verleden GM, Malfroot A, Vandenplas Y, et al. Gastro-oesophageal reflux and aspiration of gastric contents in adult patients with cystic fibrosis. Gut 2008;in press.

10. Rosen R, Nurko S. The importance of multichannel intraluminal impedance in the evaluation of children with persistent respiratory symptoms. Am J Gastroenterol 2004 Dec;99(12):2452-8.

11. Thilmany C, Beck-Ripp J, Griese M. Acid and non-acid gastro-esophageal refluxes in children with chronic pulmonary diseases. Respir Med 2007 May;101(5):969-76.

12. Wenzl TG, Schenke S, Peschgens T, Silny J, Heimann G, Skopnik H. Association of apnea and nonacid gastroesophageal reflux in infants: Investigations with the intraluminal impedance technique. Pediatr Pulmonol 2001 Feb;31(2):144-9.

13. Loots CM, Benninga MA, Davidson GP, Omari TI. Addition of pH-impedance monitoring to standard $\mathrm{pH}$ monitoring increases the yield of symptom association analysis in infants and children with gastroesophageal reflux. J Pediatr 2009 Feb;154(2):248-52.

14. Laukka MA, Cameron AJ, Schei AJ. Gastroesophageal reflux and chronic cough: which comes first? J Clin Gastroenterol 1994 Sep;19(2):100-4.

15. Paterson WG, Murat BW. Combined ambulatory esophageal manometry and dualprobe $\mathrm{pH}$-metry in evaluation of patients with chronic unexplained cough. Dig Dis Sci 1994 May;39(5):1117-25. 
16. Sifrim D, Dupont L, Blondeau K, Zhang X, Tack J, Janssens J. Weakly acidic reflux in patients with chronic unexplained cough during 24 hour pressure, $\mathrm{pH}$, and impedance monitoring. Gut 2005 Apr;54(4):449-54.

17. Merchant JM, Masters BI, Taylor SM, Cox NC, Seymour GJ, Chang AB. Evaluation and Outcome of Young Children With Chronic Cough. Chest 2003; 129: 1132-1141

18. Sifrim D, Castell D, Dent J, Kahrilas PJ. Gastro-oesophageal reflux monitoring: review and consensus report on detection and definitions of acid, non-acid, and gas reflux. Gut 2004 Jul;53(7):1024-31.

19. Rudolph CD, Mazur LJ, Liptak GS, Baker RD, Boyle JT, Colletti RB, et al. Guidelines for evaluation and treatment of gastroesophageal reflux in infants and children: recommendations of the North American Society for Pediatric Gastroenterology and Nutrition. J Pediatr Gastroenterol Nutr 2001;32 Suppl 2:S131.

20. Lam HG, Breumelhof R, Roelofs JM, Van Berge Henegouwen GP, Smout AJ. What is the optimal time window in symptom analysis of 24-hour esophageal pressure and pH data? Dig Dis Sci 1994 Feb;39(2):402-9.

21. Weusten BL, Roelofs JM, Akkermans LM, Van Berge-Henegouwen GP, Smout AJ. The symptom-association probability: an improved method for symptom analysis of 24-hour esophageal pH data. Gastroenterology 1994 Dec;107(6):1741-5. 
22. Wunderlich AW, Murray JA. Temporal correlation between chronic cough and gastroesophageal reflux disease. Dig Dis Sci 2003 Jun;48(6):1050-6.

23. Tolia V, Vandenplas Y. Systematic review: the extra-oesophageal symptoms of gastro-oesophageal reflux disease in children. Aliment Pharmacol Ther 2009 Feb $1 ; 29(3): 258-72$.

24. Fitzgerald JM, Allen CJ, Craven MA, Newhouse MT. Chronic cough and gastroesophageal reflux. CMAJ 1989 Mar 1;140(5):520-4.

25. Ing AJ, Ngu MC, Breslin AB. Chronic persistent cough and gastro-oesophageal reflux. Thorax $1991 \mathrm{Jul} ; 46(7): 479-83$.

26. Silny J. Intraluminal multiple electric impedance procedure for measurement of gastrointestinal motility. 3, 151-62. 1991.

27. Rudolph CD, Mazur Lj, Liptak GS, et al. Guidelines for evaluation and treatment of gastroesophageal reflux in infants and children: Recommendations of the North American Society for pediatric gastroenterology and Nutrition. J Pediatr Gastroenterol Nutr 2001;32:S1-31.

28. Mahajan L, Wyllie R, Oliva L, Balsells F, Steffen R, Kay M. Reproducibility of 24houur intraesophageal pH monitoring in pediatric patients. Pediatrics. 1998 Feb; 101(2):260-3.

29. Tutuian R, Mainie I, Agrawal A, Adams D, Castell DO. Nonacid reflux in patients with chronic cough on acid-suppressive therapy. Chest 2006 Aug;130(2):386-91. 
30. Koek GH, Sifrim D, Lerut T, Janssens J, Tack J. Effect of the GABA(B) agonist baclofen in patients with symptoms and duodeno-gastro-oesophageal reflux refractory to proton pump inhibitors. Gut 2003 Oct;52(10):1397-402.

31. Lidums I, Lehmann A, Checklin H, Dent J, Holloway RH. Control of transient lower esophageal sphincter relaxations and reflux by the $\mathrm{GABA}(\mathrm{B})$ agonist baclofen in normal subjects. Gastroenterology 2000 Jan;118(1):7-13.

32. Sifrim D, Tack J, Arts J, Caenepeel P, Zhang X, Silny J, et al. Baclofen reduces weakly acidic reflux in ambulant patients with GERD. Gastroenterology 2005 Apr;128(4):A531.

John Wiley \& Sons, Inc. 


\section{Figure legends}

Figure 1: Example of cough "induced" by weakly acidic reflux. Impedance shows a retrograde flow of liquid up to channel 1, with the esophageal pH remaining above 4 (weakly acidic reflux). 45 seconds after the reflux, event, the manometry shows a cough burst, characterized by a rapid increase in pressure.

Figure 2: Example of cough provoking reflux. The manometry tracing shows a cough burst, immediately followed by a retrograde flow of liquid in the impedance tracing. During reflux, the esophageal pH drops below 4 (acid reflux). * acid exposure provoked by coughing (13 sec).

${ }^{* *}$ volume exposure provoked by coughing $(9 \mathrm{sec})$.

Figure 3: Flow chart displaying the different subgroups of patients identified by the study. From the patients without increased esophageal acid exposure, we identified a subgroup $(n=9)$ that had a +SAP for reflux-cough. 
1

Table 1: Work-up performed in all patients before the impedance-pH recording. Work-up showed no underlying etiological diagnosis for chronic cough, or in case of clinical suspected asthmatic cough, there was no response to a correct treatment trial of at least 4 weeks.

\begin{tabular}{|l|}
\hline History \\
\hline Complete physical examination \\
Blood tests: \\
- White blood differential cell counting \\
- C-reactive protein \\
- Erythrocyte sedimentation rate \\
- Viral serology and anti-Mycoplasma antibodies \\
- Immunoglobulins and IgG subclasses \\
- Specific IgE for house dust mites, cat and dog, milk, \\
$\quad$ egg, fish, peanut (RAST Phadebas) \\
Other tests: \\
- Skin-prick testing for common allergens \\
- Swab for Bordetella pertussis PCR and culture \\
- Tuberculin test (Mantoux intradermal test) \\
- Sweat testing (Gibson-Cook method) \\
- Lung function testing (with peak-flow measurements) in \\
- Children older than 3 years \\
- Chest radiographs
\end{tabular}


Table 2: Reflux characteristics in children with chronic unexplained cough during the total study period and in the recumbent position.

Results are expressed as median (range).

\begin{tabular}{|l|c|c|}
\hline & \multicolumn{2}{|c|}{ Children with chronic cough } \\
& Total & Recumbent \\
\hline Acid exposure (\%) & $2.3(0.0-15.6)$ & $0.3(0-21.1)$ \\
Volume exposure (\%) & $0.8(0.0-8.0)$ & $0.1(0.0-7.5)$ \\
Total nr of reflux events & $30(5-116)$ & $5(0-46)$ \\
Nr of acid reflux & $18(0-49)$ & $3(0-32)$ \\
Nr of weakly acidic reflux & $12(3-78)$ & $2(0-14)$ \\
Nr of weakly alkaline reflux & $0(0-21)$ & $0(0-0)$ \\
$\%$ of mixed reflux & $33(3.4-82.6)$ & $10(0-66.7)$ \\
Nr of episodes with high proximal extent & $8(0-66)$ & $1(0-25)$ \\
\hline
\end{tabular}

John Wiley \& Sons, Inc. 
Table 3: Comparison of cough events indicated in the patient diary and objectively recorded with gastroesophageal manometry

\begin{tabular}{|l|c|c|}
\hline & Diary & Manometry \\
\hline Total nr of coughs & 566 & 1424 \\
Nr of nocturnal coughs (\%) & $179(31.6)$ & $414(29)$ \\
Nr of coughs preceded by reflux (\%) & $51(9)$ & $145(10.2)$ \\
Nr of patients with +SAP & 6 & 10 \\
+SAP acid reflux & 4 & 1 \\
+SAP non-acid reflux & 2 & 6 \\
+SAP acid + non-acid reflux & 0 & 3 \\
\hline
\end{tabular}

John Wiley \& Sons, Inc. 


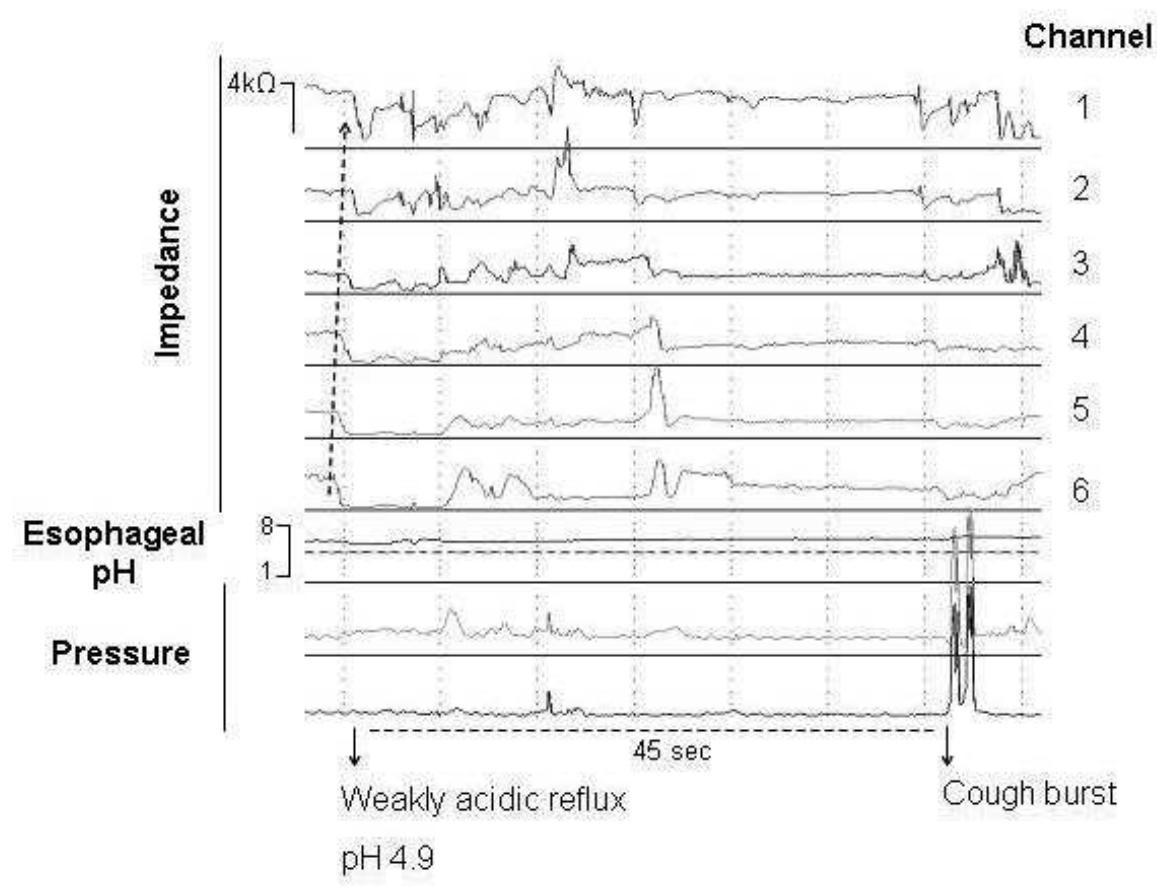

Figure 1

$169 \times 136 \mathrm{~mm}(96 \times 96$ DPI)

John Wiley \& Sons, Inc. 
Figure 2 $150 \times 172 \mathrm{~mm}(96 \times 96 \mathrm{DPI})$

John Wiley \& Sons, Inc. 
Figure 3

$254 \times 190 \mathrm{~mm}(96 \times 96$ DPI $)$

John Wiley \& Sons, Inc. 